\title{
Comparison of Oral Misoprostol with Intramuscular Oxytocin in the Active Management of Third Stage of Labour
}

\author{
Kaudel S', Rana $\mathrm{A}^{2}$, Ojha $\mathrm{N}^{2}$ \\ ${ }^{1}$ Department of Obstetrics and Gynaecology, Chitwan Medical College, Chitwan, Nepal, ${ }^{2}$ Department of Obstetrics and \\ Gynaecology, Tribhuvan University Teaching Hospital, Kathmandu, Nepal.
}

Received: June 05, 2014; Accepted: January 20, 2015

\begin{abstract}
Aims: This study aimed at comparing the efficacy of oral misoprostol $600 \mathrm{mcg}$ with intramuscular oxytocin 10 IU in the active management of third stage of labour.

Methods: This prospective comparative study was performed in Tribhuvan University Teaching Hospital to compare the efficacy of oral misoprostol with intramuscular oxytocin in the third stage of labour for the prevention of postpartum hemorrhage. One hundred and twenty women without risk of PPH were randomly allocated to receive either 600 mcg misoprostol orally (Group A) or 10 unit of oxytocin intramuscularly (Group B) within 1 minute of delivery. The efficacy and the safety of these two drugs were analyzed on the basis of percentages fall in hemoglobin $(\mathrm{Hb})$ and hematocrit $(\mathrm{Hct})$ level from before delivery to 8 completed hours after delivery, need for additional uterotonic agents, need for exploration and uterine evacuation, need for blood transfusion, duration of third stage of labour and the numbers of retained placenta and need for MRP.
\end{abstract}

Results: Oral misoprostol was observed to be equally effective as intramuscular oxytocin in prevention of post-partum hemorrhage (PPH). There was no statistical difference in the duration of third stage of labour, need for additional uterotonics, need for uterine exploration/evacuation and need for blood transfusion in the two groups.

Conclusions: Routine use of oral misoprostol $600 \mathrm{mcg}$ appears to be as effective as $10 \mathrm{IU}$ intramuscular oxytocin in minimizing blood loss during the third stage of labour.

Keywords: active management of third stage of labour; misoprostol; oxytocin.

\section{INTRODUCTION}

Globally, misoprostol which first came into use for prevention of peptic ulcer disease was found useful for termination of pregnancy and then as a miracle drug in the prevention of PPH. But the drug which is being used for this purpose universally is oxytocin for almost half a decade after being introduced in 1963 at the National Maternity Hospital in Dublin, Ireland. ${ }^{1}$ Active management of third stage of labour (AMTSL) means expediting the process by early cord clamping, administration of a uterotonic, delivery of placenta by controlled cord traction following uterine contraction and finally uterine massage after delivery of the complete placenta. ${ }^{2}$ Through this, shortening of third stage of labour by $50 \%$ and reduction of blood

\section{CORRESPONDENCE}

Dr Sudeep Kaudel

Department of Obstetrics and Gynaecology, Chitwan Medical College, Chitwan, Nepal.

Email: sudeepkaudel@gmail.com

Phone: +977-9855063888 loss by $20 \%$ have been evidenced, hence AMTSL has been now adopted worldwide as a strategy to reduce excessive blood loss during childbirth. ${ }^{3}$

The use of oxytocin in the AMTSL is fraught with problems of storage, fake and substandard drugs, and the need for trained staff in order to administer it. Misoprostol on the other hand offers several advantages over oxytocin including a shelf life of several years, stability at high temperature, oral administration, minimal side effects, and that it can be administered to hypertensive patients. ${ }^{4}$ Based on this framework the present study is aimed at comparing the efficacy and safety of oral misoprostol with intramuscular oxytocin in the active management of third stage of labour.

\section{METHODS}

This was a prospective study conducted at the labour room and maternity unit in the Department of Obstetrics and Gynaecology, Tribhuvan University Teaching Hospital from $13^{\text {th }}$ April 2012 to $13^{\text {th }}$ April 
2013. During the one year study period, 4304 women delivered at TUTH, out of them 2579 (59.9\%) had normal vaginal delivery. Among them 120 women $(4.6 \%)$ were enrolled in the study. Later 12 of them were excluded because of instrumental delivery (10) and caesarean section (2). Finally 108 women, 54 in each group Group A (600 mcg oral misoprostol) and Group B (10 U intramuscular oxytocin) were studied.

All women with parity of $<5$, having singleton live pregnancy at or above 37 weeks of gestation, in cephalic presentation, undergoing spontaneous onset of labour and spontaneous vaginal delivery without any complicating factors were included in the study. Informed consent was taken for collection of blood sample for initial hemoglobin $(\mathrm{Hb})$ and hematocrit (Hct) estimation. Then the women were allotted randomly into two groups at the second stage of labour when delivery was imminent by picking an envelope from a capped plastic container with 108 equal sized folded paper envelopes. Deliveries were conducted in the lithotomy or dorsal position and allocated drug was administered immediately after the delivery of the baby. Early clamping of the umbilical cord and controlled cord traction was done immediately after the delivery of the baby without waiting for the signs of placental separation by Brandt and Andrew's method in all the groups.

If the placenta was not delivered within 30 minutes of the delivery of the baby, a diagnosis of retained placenta was made and it was removed manually. Uterine massage was done for about 10 - 15 minutes after expulsion of placenta until the uterus became well contracted in all the women and then the women were taught to massage their uterus every 15 minutes for 2 hours after delivery. All placentas were examined to rule out retained bits of placenta and membranes. Episiotomy wounds, tears and lacerations if present were immediately repaired. The amount of blood loss was visually estimated at the end of the delivery and any additional loss was added up before transferring the patient to the ward after 1 hour of observation in the labour room. Once the hemostasis was ensured and the uterus sufficiently contracted, the women were shifted from the labour table and monitored in the labour room for one hour following delivery. At the end of 1 hour the women were asked about the side effects attributable to the drug and this was recorded if present. When the women were hemodynamically stable, the uterus well contracted and no significant vaginal bleeding, they were transferred to the maternity ward. The level of hematocrit and hemoglobin was measured 8 hours postpartum from the maternity ward. The women were followed up till discharge. Comparison of difference in hematocrit levels in both the groups was maintained. Delayed hemorrhage in the ward requiring exploration, need for additional uterotonics and need for blood transfusion were recorded in the postnatal ward.

After the primary data collection, daily entries of these data were put in the master chart. Analysis was done with the help of a computer using Chi-square $\left(\mathrm{x}^{2}\right)$ test and student's T-test. A P value of $<0.05$ was regarded as statistically significant. The computer programme used was SPSS version 19.

\section{RESULTS}

The two groups were balanced at randomization for potential confounding factors like age, parity, booking status and gestational age at delivery. The two groups were also comparable with regard to baseline prognostic labour characteristics like duration of labour, mode of delivery, mean birth weight of the baby and the mean placental weight. The duration of third stage of labour in misoprostol group was also not statistically different to that of oxytocin group.

The visually estimated third stage blood loss ranged from 50 to $300 \mathrm{ml}$ (Table 1).

\begin{tabular}{|llll|}
\hline \multicolumn{4}{l}{ Table 1. Visually estimated blood loss in third stage of } \\
labour ( $=108)$. \\
\hline $\begin{array}{l}\text { Blood loss } \\
\text { (ml) }\end{array}$ & Misoprostol & Oxytocin & P value \\
$0-100$ & 38 & 37 & \\
$101-200$ & 12 & 16 & 0.324 \\
$201-300$ & 4 & 1 & \\
\hline
\end{tabular}

The average blood loss observed was $115.5 \mathrm{ml}$ in misoprostol group and $118 \mathrm{ml}$ in oxytocin group and this observation was statistically not significant ( $p$ 0.324) (Table 2).

\begin{tabular}{|llc|}
\hline $\begin{array}{l}\text { Table 2. Average blood loss in third stage of labour } \\
(\mathrm{n}=108) .\end{array}$ & Oxytocin \\
\hline Group & Misoprostol & 118 \\
$\begin{array}{l}\text { Average blood } \\
\text { loss }(\mathrm{ml})\end{array}$ & 115.5 & \\
\hline
\end{tabular}


Mean change in $\mathrm{Hb}$ level in misoprostol group was $0.56 \pm 0.35 \mathrm{gm} / \mathrm{dl}$ as compared to $0.46 \pm 0.29$ $\mathrm{gm} / \mathrm{dl}$ in oxytocin group, which was statistically insignificant (p-0.222). Similarly, mean change in Hct level in the misoprostol and oxytocin group was $0.68 \pm 0.30 \%$ and $0.75 \pm 0.27 \%$ respectively, which was comparable ( $\mathrm{p}-0.257)$. There was no incidence of PPH (peripartum fall in $\mathrm{Hb}$ of $10 \%$ ) in both the groups (Table 3).

\begin{tabular}{|c|c|c|c|}
\hline \multirow{2}{*}{ Variables } & \multicolumn{2}{|l|}{ Study group } & \multirow[t]{2}{*}{ P-value } \\
\hline & Misoprostol & Oxytocin & \\
\hline \multicolumn{4}{|c|}{ Hematocrit (\%) } \\
\hline Pre-delivery & $36.52 \pm 3.09$ & $36.39 \pm 2.79$ & \\
\hline Post-delivery & $35.85 \pm 3.10$ & $35.63 \pm 2.74$ & \\
\hline Change & $0.68 \pm 0.30$ & $0.75 \pm 0.27$ & 0.257 \\
\hline \multicolumn{4}{|c|}{ Hemoglobin $(\mathrm{g} / \mathrm{dL})$} \\
\hline Pre-delivery & $12.33 \pm 1.16$ & $12.45 \pm 1.07$ & \\
\hline Post-delivery & $11.83 \pm 1.28$ & $12.01 \pm 1.04$ & \\
\hline Change & $0.56 \pm 0.35$ & $0.46 \pm 0.29$ & 0.222 \\
\hline
\end{tabular}

Four women each in the misoprostol and oxytocin group required additional uterotonics and this was comparable. Those women needing extra uterotonics in misoprostol group responded to additional oxytocin infusion, one requiring 10 unit infusion and other required double the concentration. Two women in oxytocin group required extra oxytocin infusion whereas two women needed rectal misoprostol and injection methergin on the top of oxytocin infusion but were statistically insignificant (Table 4). No woman in either group required uterine exploration or evacuation and there was no need of blood transfusion in both groups.

\begin{tabular}{|c|c|c|c|}
\hline $\begin{array}{l}\text { Additional } \\
\text { uterotonics used }\end{array}$ & Misoprostol & Oxytocin & $P$ value \\
\hline $\begin{array}{l}10 \mathrm{U} \text { Oxytocin } \\
\text { infusion }\end{array}$ & 3 & 1 & \multirow{4}{*}{0.324} \\
\hline $\begin{array}{l}20 \text { U Oxytocin } \\
\text { infusion }\end{array}$ & 1 & 1 & \\
\hline $\begin{array}{l}20 \text { U Oxytocin } \\
\text { infusion }+800 \\
\text { meg misoprostol } \\
\mathrm{P} / \mathrm{R}\end{array}$ & 0 & 1 & \\
\hline $\begin{array}{l}20 \mathrm{U} \text { Oxytocin } \\
\text { infusion }+800 \mathrm{mcg} \\
\text { misoprostol } \mathrm{P} / \mathrm{R}+1 \\
\text { amp methergin }\end{array}$ & 0 & 1 & \\
\hline
\end{tabular}

Nine women in misoprostol group had side effects whereas none in oxytocin group experienced sideeffects and it was statistically significant (p-0.002). Out of these nine women, six women $(11.1 \%)$ developed shivering within 1 hour postpartum. One woman $(1.8 \%)$ developed only fever as a side effect whereas two women $(3.7 \%)$ had shivering and fever (max. temp 100'F) (Table 5).

\begin{tabular}{|c|c|c|c|}
\hline Variable & Misoprostol & Oxytocin & P value \\
\hline Shivering & 6 & 0 & \multirow{3}{*}{0.002} \\
\hline $\begin{array}{l}\text { Shivering } \\
+ \text { fever }\end{array}$ & 2 & 0 & \\
\hline Fever & 1 & 0 & \\
\hline
\end{tabular}

\section{DISCUSSION}

Misoprostol in AMTSL has been reported to effectively reduce the incidence of primary PPH from $18 \%$ to $5 \%$. In addition, the time for administration of therapeutic drugs is reduced from 15 minutes to five minutes. ${ }^{5,6}$ This practice has become a standard of obstetric care, and misoprostol has emerged as a promising treatment alternative. ${ }^{7-9}$ In this study, 600 mcg oral misoprostol was compared with 10 unit IM oxytocin for AMTSL and this dose of misoprostol is recommended by WHO for AMTSL when standard oxytocin is not available. This study found that there was no statistical significance between the effectiveness of these drugs in AMTSL and same result was shown by Oboro et al. ${ }^{10}$ in Nigeria which concluded that oral misoprostol $600 \mathrm{mcg}$ can replace 10 unit intramuscular oxytocin in reducing postpartum 
hemorrhage in low-risk women, in developing countries. Several other routes of misoprostol like sublingual, vaginal, rectal and buccal have been compared and different doses ranging from 400 to 1000 mcg have been tried in AMTSL. ${ }^{11-13}$

In the misoprostol group, mean duration of third stage of labour was $4.76 \pm 1.69$ min whereas it was $4.39 \pm$ $1.37 \mathrm{~min}$ in the oxytocin group without any statistical significance (p-0.935) and similar result was obtained in three other comparative studies. ${ }^{12,14,15}$ The present study supports that the duration of third stage of labor is reduced by using uterotonics hence reducing the amount of blood loss.

The amount of blood loss was statistically similar in both groups. The mean blood loss in the misoprostol group was $115.5 \pm 39.5 \mathrm{ml}$ and in oxytocin group, it was $118 \pm 48.6 \mathrm{ml}$, which was less than the blood loss in other studies. ${ }^{16-18}$

This might be due to visual estimation of blood loss in the index study whereas other studies have used objective measurement of blood loss by placing drape under the buttocks before delivery and removing it after 1 hour postpartum. Most of the studies were unable to find the statistical significance in the blood loss while comparing these drugs in AMTSL. ${ }^{11,15,19}$

Numerically, the amount of blood loss was higher in the oxytocin group in comparison to misoprostol group in this study but this was statistically insignificant ( $p$ - 0.324). One patient on each group had blood loss of $300 \mathrm{ml}$ which was the maximum blood loss estimated visually but visual estimation generally underestimates blood loss by $30 \%$, which is clinically inadequate and has presented practical problem.

Several other studies ${ }^{8,20}$ have also observed that peripartum fall in hematocrit level by at least $10 \%$ from before delivery to 24 hours after delivery, is a better definition than the volume criteria of PPH. In this study the efficacy of the two regimes in the active management of the third stage of labour was mainly based on assessment of the degree of fall in hematocrit following delivery in the two groups. There was no statistical difference in the average fall of hematocrit in between misoprostol and oxytocin group $(0.68 \pm$ $0.3 \%$ versus $0.75 \pm 0.27 \%$ ) such that there was no incidence of PPH in these two groups by hematocrit criteria ( $p$ value- 0.257 ). These observations show that oral misoprostol and intramuscular oxytocin are equally efficacious for AMTSL and this finding is consistent with data from another similar comparative study. ${ }^{11}$

Additional uterotonics were administered in eight women, four in each group. Those women needing extra uterotonics in misoprostol group responded to additional oxytocin infusion only; whereas women in oxytocin group required either oxytocin infusion, or rectal misoprostol and injection methergin on the top of oxytocin infusion but this was statistically insignificant.

A similar comparative study done in Ghana in 2002 has shown less use of additional uterotonics in the misoprostol group as compared in the oxytocin group $(7.1 \%$ vs $9.3 \%)$, probably because of use of higher dose of misoprostol $(800 \mathrm{mcg})$ in that study as compared to the index study but the result was insignificant. ${ }^{18}$

Next additional parameter in assessment of efficacy of the two regimes was the need for blood transfusion following delivery and the need for exploration and uterine evacuation following delivery in the two groups. Fortunately no women required blood transfusion or uterine exploration/evacuation in these groups as they were well booked and had high hemoglobin and hematocrit before delivery. A similar comparative study done in India in 2011 showed that $1.9 \%$ of women in misoprostol and $1.1 \%$ of women in oxytocin required blood transfusion whereas MRP was needed in less than $1 \%$ in both the cases without bearing any significance. ${ }^{16}$ As lesser number of women had participated in the index study, this might be the cause for no requirement of blood transfusion and MRP.

Regarding the side effects of oral misoprostol and intramuscular oxytocin, there were no serious side effects in this study. All the adverse effects were mild and they subsided spontaneously and none of the women required any medications for these effects. 
In this study, the analysis of side effects of the two uterotonics revealed the presence of side-effects only in misoprostol group.

Nine women in misoprostol group had side effects and it was statistically significant (p-0.002). Out of these nine women, six women $(11.11 \%)$ developed shivering within 1 hour postpartum and one woman $(1.8 \%)$ developed only fever as a side effect whereas two women $(3.7 \%)$ had shivering and fever ( $\max$ temp 100 'F).

\section{CONCLUSIONS}

Misoprostol (oral $600 \mathrm{mcg}$ ) and oxytocin (IM 10 unit) were equally effective in AMTSL in this comparative study as there was no PPH in both the groups Misoprostol had lesser blood loss than oxytocin but this was not statistically significant. Oxytocin had the additional advantage of nil side effects bearing statistical significance. Hence, misoprostol which is as effective as oxytocin can be adopted for the active management of third stage of labour, with minimal self-limiting side effects.

\section{DISCLOSURE}

The authors report no conflicts of interest in this work. No violation of human rights and safety.

Funding: Nil

\section{REFERENCES}

1. Chanrachakul B, Herabutya Y, Panburana P. Active management of labor: is it suitable for a developing country? Int J Gynaecol Obstet. 2001;72(3):229-34.

2. Oladapo OT, Akinola OI, Fawole AO, Adeyemi AS, Adegbola $\mathrm{O}$, Loto OM, et al. Active management of third stage of labor: evidence versus practice. Acta Obstetricia et gynecologica Scandinavica. 2009;88:1252-60.

3. Prendiville W, Elbourne D, McDonald S. Active versus expectant management in the third stage of labour. Cochrane Database Syst Rev. 2000;CD000007.

4. Edmonds D, editor. Dewhurst's textbook of Obstetrics and Gynaecology for Postgraduate. 6th ed. Oxford: Blackwell; 2000. p. 330-41.

5. Amant F, Spitz B, Timmerman D, Corremans A, Van Assche FA. Misoprostol compared with methylergometrine for the prevention of postpartum haemorrhage: a double-blind randomised trial. Br J Obstet Gynaecol. 1999;106:1066-70.

6. Amant F. The misoprostol third stage study: a randomised controlled comparison between orally administered misoprostol and standard management: a double-blind placebo controlled randomised trial of misoprostol and oxytocin in the management of the third stage labo. Br J Obstet Gynaecol. 2001;108:338-9.

7. Oboro V, Tabowei T. A randomized controlled trial of misoprostol versus oxytocin in the active management of the third stage of labor. J Obstet Gynaecol. 2003;23(1):13-6.

8. Bugalho A, Daniel A, Faundes A, Cunha M. Misoprostol for prevention of postpartum hemorrhage. Int J Gynaecol Obstet. 2001;73:1-6.

9. Bellad MB, Tara D, Ganachari MS, Mallapur MD, Goudar SS, Kodkany BS, et al. Prevention of postpartum haemorrhage with sublingual misoprostol or oxytocin: a doubleblind randomised controlled trial. Br J Obstet Gynaecol. 2012;119(8):975-82

10. Gulmezoglu A, Forna F, Villar J, Hofmeyr G. Prostaglandin for prevention of postpartum hemorrhage. Cochrane Libr. $2002 ;(3)$
11. Gülmezoglu AM, Villar J, Thi N, Ngoc N, Piaggio G, Carrol $\mathrm{G}$, et al. WHO multicentre randomised trial of misoprostol in the management of the third stage of labour. Lancet. 2001;358:689-95.

12. Ujah IA, Aisien OA, Mutihir JT, Vanderjaqt DJ, Glew RH, Uguru VE. Factors contributing to maternal mortality in north-central Nigeria: a seventeen-year review. Afr J Reprod Health. 2005;9:27-40

13. Shrestha A, Dongol A, Chawla CD, Adhikari RK. Recta misoprostol versus intramuscular oxytocin for prevention of post partum hemorrhage. Kathmandu Univ Med J. 2011;9(1):8-12.

14. Afolabi EO, Kuti O, Orji EO, Ogunniyi SO. Oral misoprosto versus intramuscular oxytocin in the active management of the third stage of labour. Singapore Med J. 2010;51(3):20711 .

15. Sultana N, Khatun M. Misoprostol versus oxytocin in the active management of the third stage of labour. J Bangladesh Coll Phys Surg. 2007;25(2):2-5

16. Chaudhuri P, Biswas J, Mandal A. Sublingual misoprosto versus intramuscular oxytocin for prevention of postpartum hemorrhage in low-risk women. Int $\mathrm{J}$ Gynaecol Obstet. 2012;116(2):138-42.

17. Walley RL, Wilson JB, Crane JM, Matthews K, Sawyer E, Hutchens D. A double-blind placebo controlled randomised trial of misoprostol and oxytocin in the management of the third stage of labour. Br J Obstet Gynaecol. 2000;107(9):11115 .

18. Parsons SM, Walley RL, Crane JMG, Matthews K, Hutchen D. Oral misoprostol versus oxytocin in the management of the third stage of labour. J Obstet Gynaecol Can. 2006;28(1):20

19. Singhal SR, Gupta N, Nanda S. Sublingual Misoprosto versus Intramuscular Oxytocin in the Active Management of Third Stage of Labor. JSAFOG. 2010;2(December):199-202.

20. Bajwa SK, Bajwa SJS, Kaur H, Goraya SPS, Singh A, Kaurishar H. Management of third stage of labor with misoprostol: a comparison of three routes of administration. Perspect Clin Res. 2012;3(3):102-8. 